\title{
Régimen civil de la propiedad cooperativa en Cuba
}

\author{
Avelino Fernández Peiso \\ Dr. en Ciencias Jurídicas y Profesor Titular Consultante \\ Universidad Carlos Rafael Rodríguez (Cienfuegos, Cuba)
}

DOI: $10.1387 /$ reves. 15265

Fecha de entrada: 05/03/2014

Fecha de aceptación: 20/05/2015

Sumario: 1. Introducción. 2. De la propiedad y el patrimonio cooperativo. 3. De la naturaleza de la propiedad cooperativa. 4. Del contenido de la propiedad cooperativa. 5. Breves acerca del contenido del Derecho de Propiedad Cooperativa. 6. Posesión, uso y disfrute en las cooperativas agropecuarias. 7. Posesión, uso, disfrute y disposición en las Cooperativas No Agropecuarias (CNA). 8. A modo de síntesis conclusiva. 9. Bibliografía.

\section{Resumen:}

El ambiente cooperativo nacional ha presentado un panorama normativo inadecuado; incrementado, diversificado y disímil desde la introducción de las Cooperativas no Agropecuarias que, además, le estampó desigualadas concepciones de la naturaleza, contenido y fines cooperativos; incursionar en la categoría propiedad cooperativa regulada en los artículos 145 y 146 del Código Civil y lo desarrollado en sus normas especiales, a la luz de este ambiente legal cooperativo, conducen a determinar la naturaleza obligacional de su contenido y sus consecuencias; su análisis, desde lo sustantivo y teórico doctrinal, muestra las tendencias, carencias, disfuncionalidades y necesidades, entre ellas la de promulgar la norma general de cooperativas; ese es el cometido del presente trabajo.

\section{Palabras clave:}

cooperativas, propiedad cooperativa, Cuba, régimen civil.

\section{Claves ECONLIT}

$\mathrm{P} 130, \mathrm{P} 140$ 


\section{Introducción}

No es usual, en los estudios comparados de las Constituciones y Códigos Civiles de países latinoamericanos, ${ }^{1}$ la modalidad subjetiva de la propiedad cooperativa direccionada, en exclusiva, a lo agrario que sigue la Constitución de la República de Cuba $(\mathrm{CR})^{2}$; y, con fortuna por lo que se apreciará, reglado en genérico, por el Código Civil $(\mathrm{CC})^{3} \mathrm{cu}-$ bano.

Así, en la redacción del artículo 20 de la Constitución de la República, que pudo haber sido más afortunada, ${ }^{4}$ se distinguen de manera diáfana dos

${ }^{1}$ Constituciones de Bolivia; Nicaragua; Chile; Costa Rica; México; Uruguay: unos solo mencionan otros ni siquiera eso, tal tipo de propiedad; sus Códigos Civiles no la refieren.

2 Ar. 20, Constitución de la República de Cuba:

«Los agricultores pequeños tienen derecho a asociarse entre sí, en la forma y con los requisitos que establece la ley, tanto a los fines de la producción agropecuaria como a los de obtención de créditos y servicios estatales.

Se autoriza la organización de cooperativas de producción agropecuaria en los casos y en la forma que la ley establece. Esta propiedad cooperativa es reconocida por el Estado y constituye una forma avanzada y eficiente de producción socialista.

Las cooperativas de producción agropecuaria administran, poseen, usan y disponen de los bienes de su propiedad, de acuerdo con lo establecido en la ley y en sus reglamentos. Las tierras de las cooperativas no pueden ser embargadas ni gravadas y su propiedad puede ser transferida a otras cooperativas o al Estado, por las causas y según el procedimiento establecido en la ley.

El Estado brinda todo el apoyo posible a esta forma de producción agropecuaria.»

3 Código Civil de la República de Cuba:

«ARTÍCULO 145. La propiedad cooperativa es reconocida por el Estado en cuanto contribuye al desarrollo de la economía nacional y constituye una forma de propiedad colectiva.

ARTÍCULO 146. Las cooperativas poseen, usan, disfrutan y disponen de los bienes de su propiedad de acuerdo con lo establecido en la ley, en sus reglamentos y en otras disposiciones legales.»

${ }^{4}$ Redacción reduccionista que así pudo, entre otras, ceñirse al primer párrafo y, con carácter teleológico reconocer el derecho de asociación cooperativo genérico, sin direccionarlo a sector económico alguno, condicionando la existencia del sujeto cooperativo, por supuesto, a la Ley que la regulare, como ha requerido la realidad social. De tal suerte hubiere dado cabida a las cooperativas existentes en aquellos momentos: Cooperativas de Producción Agropecuaria y Cooperativas de Créditos y Servicios; posibilitaría las surgidas luego, Unidades Básicas de Producción Cooperativa (UBPC) ; además, daría las vías a otras ni siquiera pensadas, como en la actualidad son las Cooperativas no Agropecuarias. Pues como expresa Fernandez Bulté (1996) «El Derecho tiene un sentido teleológico, en función de un fin, y no es un simple conjunto de normas para regular lo que ya existe, sino algo que se quiera que exista, de ahí que lo teleológico esté imantado a lo deontológico, el deber ser. De otra manera el Derecho es un simple relato de lo que pasa en la sociedad». 
direcciones para el asociacionismo campesino; una primaria y totalizadora consistente en el reconocimiento del derecho de asociación campesina para la constitución de cooperativas, con fines de producción agropecuaria o la obtención de créditos y servicios estatales; fue la fuente de creación de las CPA (cooperativas de producción agrícola) y las CCS (cooperativas de crédito y sevicios). ${ }^{5}$

La otra secundaria y particularizada, dirigida a admitir la propiedad de las cooperativas de producción agropecuaria, sus derechos, limitaciones y apoyo estatal; que es la fuente de una de las formas de propiedad reconocidas constitucionalmente.

El derecho de asociación cooperativa, contenido en ese primer párrafo, no ha tenido un pacífico desarrollo legislativo, en tanto el texto de la norma especial vigente ${ }^{6}$ lo ha minimizado, mientras privilegia el contenido administrativo patrimonial del propio artículo. Esta inclinación legislativa, al interpretar y aplicar el texto constitucional, tiene sus consecuencias teóricas y prácticas.

Teórica, pues erróneamente reconoce dos naturalezas distintas para una misma forma de manifestarse la relación cooperativa — como forma socialista particular y diferenciada de la estatal para organizar y gestionar la producción y los servicios - cuando refrenda la Ley, que las CPA son «una forma avanzada y eficiente de producción socialista» ${ }^{7}$; mientras determina que las CCS tan solo constituyen una «asociación voluntaria de los agricultores pequeńos.» ${ }^{8} \mathrm{Tal}$ norma desconoce las particularidades de la naturaleza societaria de la institución cooperativa en general.

Las consecuencias prácticas, derivadas de la anterior inclinación legal, determina el tratamiento administrativo a la creación, organización y de-

5 Apuntes tomados, entre otros, de la Tesis Doctoral del autor.

6 Su predecesora, Ley 36/82, de 22 de julio, Ley de Cooperativas Agropecuarias, primer cuerpo normativo cooperativo cubano, las dotó de marco legal propio y también las concibió diferenciadamente: las CPA como «la asociación voluntaria de agricultores pequeños que unen sus esfuerzos para la producción agropecuaria colectiva de carácter socialista, sobre la base de la unificación de sus tierras y demás medios de producción.»; las CCS, como «la asociación voluntaria de agricultores pequeños que mantienen la propiedad de sus respectivas fincas y demás medios de producción, así como sobre la producción que obtienen.» Ley No. 95/02.

7 «Artículo 4. La Cooperativa de Producción Agropecuaria es una entidad económica que representa una forma avanzada y eficiente de producción socialista con patrimonio y personalidad jurídica propios, constituida con la tierra y otros bienes aportados por los agricultores pequeńos, a la cual se integran otras personas, para lograr una producción agropecuaria sostenible.»

8 «Artículo 5. La Cooperativa de Créditos y Servicios es la asociación voluntaria de los agricultores pequeños que tienen la propiedad o el usufructo de sus respectivas tierras y demás medios de producción, así como sobre la producción que obtienen. Es una forma de cooperación agraria mediante la cual se tramita y viabiliza la asistencia técnica, financiera y material que el Estado brinda para aumentar la producción de los agricultores pequeńos y facilitar su comercialización. Tiene personalidad jurídica propia y responde de sus actos con su patrimonio.» 
sarrollo cooperativo agrario, lo cual redunda en que tampoco ellas hayan cubierto las necesidades y expectativas del país.

Tampoco en la tradición constitucionalista nacional se observa tal línea de pensamiento reduccionista respecto al cooperativismo, expresado, a juicio de este autor, por el discernimiento que, sobre el fenómeno cooperativo - naturaleza, contenido y alcance- obra en la Constitución de 1940, cuando en el Título Sexto «del Trabajo y la Propiedad», la colocan en la Sección Primera, "del Trabajo», artículo 175 a las Cooperativas y no en la Sección Segunda «de la Propiedad».?

Aquello fue fruto de la comprensión de que, en el fenómeno cooperativo, no es determinante la categoría propiedad, sino la forma de su gestión sobre los bienes, de su empleo; es decir, la manera de aplicar los bienes con fines no lucrativos y solidarios en el empeño de colocarlos en beneficio de los miembros y de la comunidad, ajeno a la lógica del capital y obtención de plusvalía, plus producto en el argot nacional, que resulta de la explotación del hombre por el hombre o por las instituciones, a saber: modelos empresariales — estatales, mercantiles, mixtos; individuales o colectivos-.

En el pensamiento jurídico hispano ya mucho antes, los hacedores de los Códigos de Comercio y Civil españoles del siglo xix, habían reflejado desde sus Exposiciones de Motivos tal comprensión diferenciada de las cooperativas, al no reconocerle naturaleza mercantil o civil a esta modalidad asociativa, excepto cuando se desnaturalizaran por la realización de actos lucrativos; ${ }^{10}$ basándose en consistir en una modalidad especial, diferente, que no incorporaba el lucro ${ }^{11}$ a sus fines.

\section{Racional percepción social y legal}

Por razón del desarraigo legal de las instituciones contenidas en el Código Civil derogado en 1987 y la valoración de las nuevas instituciones so-

9 Línea de pensamiento semejante que también se puso de manifiesto en ocasión del análisis de modificación del artículo 20 de la Constitución, en la Sesión de la Asamblea Nacional del Poder Popular durante 1992, donde algunos diputados hicieron hincapié por no exaltar el término "propiedad» en la redacción de dicho artículo, si no el término "forma de producción socialista». Acta del análisis de las modificaciones constitucionales de 1992 sobre el artículo 20 por la Asamblea Nacional del Poder Popular (p. 20 y 21).

${ }^{10}$ La Exposición de Motivos del Código de Comercio se pronunció por no atribuirle naturaleza mercantil cuestión fijada, como cláusula de excepción de su aplicabilidad, en el artículo 124 del aprobado Código en 1886. Por su parte la normativa civil, Código Civil de 1888 , las omitió en tanto las cooperativas no calificaban tampoco para el contrato de sociedad.

${ }^{11}$ Lucro es la ganancia o utilidades provenientes de una cosa, en este caso el capital, no del trabajo. 
cioeconómicas surgidas por la naturaleza socialista de la sociedad cubana, el nuevo Código Civil en su Disposición Final Primera dispuso que se regirían por normas especiales, entre otras, las que ocurrieren en el ámbito cooperativo, ${ }^{12}$ conservando carácter supletorio.

El mandato constitucional, génesis de la categoría «propiedad cooperativa» contenida en el CC, ${ }^{13}$ funda su reconocimiento por el Estado, al: a) contribuir a la economía nacional; $y, b)$ constituir una forma de propiedad colectiva.

Entonces, en el empeño de comentar los artículos del CC, referidos a la forma de propiedad cooperativa y su contenido — artículos 145 y 146 - se asume separado, por clases de cooperativas, el estudio de la unidad lógica contenida en el Capítulo II, Sección Tercera, Propiedad Cooperativa, derivando hacia las prescripciones que obran en las normas propias referidas al tópico de la propiedad cooperativa.

$\mathrm{Al}$ igual, y siguiendo la cualidad sectorial oficial ${ }^{14}$ que califica en la actualidad las clases de cooperativas en agropecuarias y no agropecuarias, también por normas propias, se diferenciarán en su estudio las peculiaridades del contenido de cada una bajo esa percepción.

Posición metodología que pretende mostrar, desde el análisis del régimen civil de la propiedad cooperativa, el quietismo jurídico cooperativo agropecuario, sus diferencias sustantivas y objetivas con el no agropecuario y, con ello, la imperiosa necesidad de cambiar la preceptiva legal del cooperativismo nacional, derivada tanto de la naturaleza, contenido y fines propios del cooperativismo, y del cubano en particular, como de su alta trascendencia teórica y práctica en lo ideológico, político, económico, sociológico y jurídico del socialismo que se aspira.

12 La alineación de la conformación del Código Civil, optó por desgajar una serie de instituciones civiles tradicionales y brindarle su tratamiento legal por medio de normas propias; a esos efectos se estableció en la Disposición Final Primera que: «Sin perjuicio del carácter supletorio de este Código, se rigen por la legislación especial las relaciones jurídicas relativas a la familia; los descubrimientos, inventos, innovaciones, racionalizaciones, creación de obras científicas, educacionales, literarias y artísticas; la caza y la pesca; los solares yermos; la vivienda urbana y rural; las cooperativas agropecuarias y todo lo concerniente al régimen de posesión, propiedad y herencia de la tierra y demás bienes destinados a la producción agropecuaria y forestal; los buques y aeronaves; las sociedades; los servicios de suministro de agua, gas, electricidad, telecomunicaciones y bultos postales, y los que se prestan en los bufetes colectivos, los seguros obligatorios, la contratación económica y cualesquiera otras relaciones que determine la ley.»

13 Art. 145, Código Civil.

14 Se califica así a la distinción político administrativo, legal y social de la identificación de las clases de cooperativas en correspondencia al sector de la economía hacia el que están dirigidas: agropecuario o no agropecuario, y no precisamente por la actividad que realizan. 


\section{De la propiedad y el patrimonio cooperativo}

\subsection{En las cooperativas agropecuarias}

Como se acotó por fortuna, y aunque con sustento en el artículo 20 de la Constitución, obra en el CC el artículo 145 dedicado a la propiedad cooperativa; cierto es que en la fecha de su promulgación, 16 de julio de 1987, el pensamiento político y social solo percibía cuales cooperativas a las del sector agropecuario existentes: Cooperativas de Producción Agropecuaria (CPA) y Cooperativas de Créditos y Servicios (CCS).

Tal artículo, en virtud de su redacción, posibilitó extender el alcance de sus preceptos a las posteriores Unidades Básicas de Producción Cooperativa (UBPC) desde $1993^{15}$ en que surgieron a la escena legal; así mismo, a las novedosas Cooperativas no Agropecuarias (CNA), desde el $2012,{ }^{16}$ por más, con sustento legal en el artículo 39.2 del propio Código.

En consonancia a la no percepción constitucional de la cooperativa como sujeto asociativo, la Ley $95 / 02$, contiene naturalezas y contenidos diferentes para las dos clases de cooperativas que regula, CPA y CCS, como se acotó; para las CPA ratifica la existencia de la categoría propiedad cooperativa, incluyendo la tierra, caracterizándolas como "forma avanzada de producción socialista», ${ }^{17}$ base del desarrollo económico y social y fortalecimiento de la economía nacional; las CCS, que solo alcanzan la condición de "una forma de cooperación agraria», ${ }_{18}^{18}$ también son titulares de bienes, excepto tierra, la que obra en titularidad de sus miembros, los cuales están sujetos a idénticas facultades obligatorias, como se expondrá.

Análogo ocurre para los sujetos UBPC, que creadas en $1993^{19}$, han transitado por varias normas reglamentarias, hasta la actual Resolución 574/12 20 del Ministro de la Agricultura: ellas detentan la tierra en usufructo, y son propietarias del resto de los bienes y las producciones resultantes de la explotación de la tierra.

Arrojando esta primera determinación que el universo de la propiedad cooperativa en el ámbito agrario es confuso: en las CPA, la propie-

15 Decreto Ley 142/93.

16 Decreto Ley 305/12.

17 Art. 4, Ley 95/02.

18 Art. 5, Ley 95/02.

19 Decreto Ley $142 / 93$.

${ }^{20}$ Res. 354/93; 688/97; 629/04 del Ministro de la Agricultura y Res. 160/93; 525/03 del Ministro del Azúcar. 
dad se considera la base de su desarrollo, estando su patrimonio integrado por la propiedad formal de las tierra, los bienes agropecuarios, así como de las resultas de las tierras recibidas en usufructo; en las CCS, aunque no es manifiesta la propiedad de sus bienes, se evidencia de su patrimonio integrado por bienes agropecuarios y las resultas de las plantaciones y producciones de las tierras recibidas en usufructo; las UBPC, son usufructuarias de tierras estatales y propietarias de los bienes agropecuarios y las resultas de esas tierras recibidas en usufructo; bienes de su propiedad que integran su patrimonio.

Es así que, con sustento en ese patrimonio, los sujetos cooperativos CPA, CCS y UBPC, establecen las relaciones jurídicas por obra de la conjunción de sus dos elementos: el activo, compuesto por bienes y derechos; y, el pasivo, cargas u obligaciones susceptibles de valoración económica. Patrimonio del que se exceptúa, en todos los casos, las tierras usufructuadas.

Relativo al derecho de propiedad de las personas naturales que las integran, denominados miembros de estas cooperativas, también ocurre otro tanto; la propiedad de bienes solo se manifiesta en los miembros de las CCS, en unos de la tierra y bienes agropecuarios, en otros solo los bienes agropecuarios; en las CPA y UBPC, los miembros solo son propietarios de su fuerza de trabajo y las retribuciones resultas de su aporte laboral en cantidad y calidad, estando impedidos de derechos sobre propiedades agrarias, de pertenencia a otro sujeto cooperativo, o la realización de otras actividades laborales. ${ }^{21}$

Ahora bien, la propiedad es uno de los componentes del patrimonio cooperativo; así pudiere pensarse que la inclusión del término "propiedad cooperativa» en la redacción del artículo tratado es adecuado en lo real y legal, mirado desde su integración al patrimonio propio de la persona jurídica: CPA, propietaria del total de los bienes; CCS, propietaria de bienes, excepto tierra; UBPC, propietaria de los bienes agropecuarios y las resultas de las tierras usufructuadas.

Pero esta percepción es discordante, desde de la concepción societaria cooperativa, donde si bien el patrimonio es elemento esencial, imprescindible, para realizar las actividades cooperativizadas, su naturaleza es de carácter utilitario y no lucrativo, generadora de beneficios justos.

Asunto de ineludible precisión, como segunda determinación, pues las concepciones CPA, CCS o UBPC se caracterizan por ser patrimonios con personalidad jurídica y no sociedades de personas; corroborado, entre otros elementos, por la integración de su patrimonio por

\footnotetext{
21 Art. 59, Ley 95/02 y art. 53, Res. 574/12 MINAG.
} 
bienes de su exclusiva propiedad, mientras sus integrantes, solo son o propietarios de su fuerza de trabajo que prestan al servicio de la cooperativa y, caso CCS, sus miembros son titulares de bienes que cumplen los planes asignados. Concepción contraria a la condición societaria y no lucrativa del cooperativismo, que bien se ilustra (Kaplan Drimer, 1973) pues la cooperativa no es propietaria de nada, ya que los socios, son propietarios particulares de sus aportes y cotitulares de todos los bienes que forman el activo de la cooperativa; ella solo es responsable por su destino; condición que además ha tenido consecuencias ideológicas teóricas y prácticas.

\subsection{En las Cooperativas no agropecuarias}

A otra percepción, sobre la propiedad, apunta la concepción de las CNA (Cooperativas no agrícolas), donde aparecen modalidades asociativas, como se precisará más adelante.

\section{De la naturaleza de la propiedad cooperativa}

\subsection{En las cooperativas agropecuarias}

Como se observa, los fundamentos por los cuales se declara la posición anterior, también está originada en el análisis dialéctico materialista de la «propiedad» desde la perspectiva de su integración en los sujetos económicos lucrativos, tanto individuales como colectivos.

Para ellos, la «propiedad» es generadora de riquezas, como resultado de la apropiación, por el propietario, de las plusvalías provenientes de su empleo, actividad o negocio, lo que en términos ideológicos y jurídicos, refrendados en la Constitución cubana, ${ }^{22}$ está prohibido ya que significa proveniente de la explotación del trabajo ajeno, cuestión diametralmente opuesta a los valores del socialismo que, a la vez, son valores del cooperativismo; he ahí la significancia de la propiedad cooperativa en el ámbito agropecuario, tal cual está regulada.

La génesis de la propiedad jurídica de las CPA, en el contexto cubano, se deriva del denominado aporte originario de la tierra y los bienes agroCuba.

22 Art. 14, primer párrafo y art. 21, segundo párrafo, Constitución de la República de 
pecuarios ${ }^{23}$ por los campesinos que inicialmente las integraron para constituirlas; ahora bien, se desnaturalizó la cualidad del aporte cooperativo, al consistir en una operación de compraventa de los bienes de aquellos integrantes originarios, que tenía tres modalidades de pagos: total, aplazado o pensión vitalicia.

Ello objetivó una concentración de bienes, tierra y demás bienes agropecuarios, en la cooperativa como propietaria única, donde los iniciáticos integrantes, ya fueren propietarios anteriores o beneficiarios de la Ley de Reforma Agraria, transmitieron por venta las propiedades de que eran titulares a la cooperativa adquirente y a la que pertenecían; es de justeza afirmar que tal proceder fue eminentemente voluntario, sin vicio de voluntad y dado por el trabajo ideológico y de concientización al campesinado.

Razón básica por la cual el miembro de la CPA, solo perciba por su trabajo el denominado anticipo - y quizás utilidades - que objetivamente posee el significado del salario, en tanto retribuye la prestación de su fuerza de trabajo personal a la cooperativa, a la vez lo excluye de responsabilidad patrimonial personal por los resultados de la labor de la cooperativa; para los posteriores integrantes de las CPA, al igual que el resto de los otros tipos de cooperativas agrarias, no existe responsabilidad de aporte obligatorios o voluntario.

Condición que permite a la cooperativa, luego de realizar las deducciones establecidas, capitalizar con las resultas del plus trabajo y, dado el caso de baja del integrante, disolución de la cooperativa u otra contingencia, no existe reintegro de la proporción de la valía del acrecimiento patrimonial de la cooperativa; los aportes iniciales fueron previamente comprados y pagados y los nuevos miembros no realizan aporte patrimonial a la cooperativa; de ese plus valor se apropia la cooperativa. De ello también deriva una forma pacífica de explotación del trabajo por la institución.

23 Bienes agropecuarios es una categoría propia del Derecho Agrario, establecida en el artículo 2.b) del Decreto Ley 125/91; abarca aquellos bienes considerados directamente vinculados a la explotación de la tierra como son los animales, las instalaciones, las plantaciones, equipos o los instrumentos destinados a la producción agropecuaria, las liquidaciones y amortizaciones y las viviendas ubicadas en la tierra de un agricultor pequeño. La terminología constitucional ha transitado desde declararlos «otros medios e instrumentos de producción» en la Constitución de la República de 24 de febrero de 1976, artículo 20; hasta «los demás bienes inmuebles y muebles que les resulten necesarios para la explotación a que se dedican» obrantes en las modificaciones constitucionales de 1992 y 2002 artículo 19, pese que en esos momentos ya era usual la categoría bienes agropecuarios. 
El caso CCS, posee otro análisis pues contiene dos titulaciones: la propiedad de la CCS, que está constreñida a una pequeña propiedad de variadas fuentes, para posibilitarle los medios patrimoniales imprescindibles para el desempeño de sus fines, en que también existe apropiación de las resultas; y la de los miembros sean propietarios de tierras y otros bienes agropecuarios o usufructuarios de tierras y propietario de bienes agropecuarios los que, por supuesto, no son propiedad de la CCS.

En ella también ocurre apropiación derivada de su actividad de intermediación secundaria ${ }^{24}$ para la gestión de créditos, servicios, venta de productos agropecuarios, etc., entre los miembros y las entidades compradoras o suministradoras de bienes y servicios; de las resultas de la explotación de las tierras recibidas en usufructo del estado y del plus producto de los trabajadores asalariados que ocasionalmente contrata para ella o los propios miembros.

Los miembros propietarios o usufructuarios de tierra, propietarios de bienes agropecuarios, perciben los beneficios directos de su explotación agraria; en el caso de los usufructuarios, a la extinción del usufructo, además perciben el pago de las bienhechurías realizadas.

En el sujeto UBPC, la connotación de la relación jurídica sobre bienes, y la génesis de la propiedad cooperativa contrasta, en tanto ellas se conformaron del fraccionamiento de la gran propiedad estatal transmitida conforme la cualidad de los bienes: la una, los inmuebles la tierra, transmitida en usufructo gratuito; la otra, los bienes agropecuarios, denominada dotación inicial, transmitidos en propiedad a través de su venta a crédito ${ }^{25}$ a la UBPC y pagado por los resultados del plusproducto del trabajo de sus miembros. De igual forma se atribuyen, en condición de propiedad, los resultados de las producciones que resulten del trabajo y el que así mismo genera plus producto, ${ }^{26} \mathrm{y}$ acrecienta el patrimonio.

24 Se califica de secundaria la intermediación de las CCS, en tanto la cooperativa no es el gestor directo de la comercialización o prestación del servicio, sino que se ciñe a mediar entre los agricultores pequeńos y los sujetos estatales realizadores de la actividad económica como entidades acopiadoras de productos agrícolas, las suministradoras o prestatarias de servicios agropecuarios; las instituciones bancarias, crediticias, de seguro para que contrate el cooperativista. En ocasiones esta intermediación secundaria se desvanece cuando las entidades estatales acopiadoras o suministradoras de productos o servicios agropecuarios contratan por gestión propia directamente con el cooperativista; en la actualidad, en virtud de ciertas regulaciones exógenas y permisivas para funciones de intermediación en la comercialización agropecuaria, ocurre un desvanecimiento mayor que tiene consecuencias actuales de incipiente mercantilización y perspectivas de desarrollo mercantil.

25 Art. 2.e), Decreto Ley 42/93.

26 Art. 2.c), Decreto Ley 42/93. 
Esa es la manera simple de objetivar el hecho real y legal de la arquitectura de la "propiedad cooperativa»; categoría que, además de tener intrínsecas y extrínsecas consecuencias teóricas, ideológicas y políticas, las posee en lo práctico: no constituyen sociedades de personas al modo cooperativo con la autonomía y responsabilidad que implica para el éxito de su desempeño, en tanto sus integrantes no resultan propietarios particulares de sus aportes y cotitulares de todos los bienes que forman el activo de la cooperativa; por ello no han dado los resultados esperados y necesitados.

\subsection{En las cooperativas no agropecuarias}

Concepción que, con las nuevas CNA, el panorama sobre la propiedad cooperativa difiere, pese las incorrecciones normativas que disfunde y omite categorías, principios, valores y fines debidos para una norma cooperativa, tanto en su concepción estructural, como de contenido, que no es objeto del presente estudio; así el Decreto Ley 305/12 introduce diversas modalidades de creación con percepción asociativa; diversas titularidades sobre los bienes que se ostenten; y diversas formas de empleo y gestión de los bienes.

Ellas pueden constituirse a) a partir de patrimonio generado por los aportes dinerarios voluntarios de los miembros bajo régimen, denominado, de propiedad colectiva; b) mediante la asociación de los miembros que conservan la propiedad de sus bienes, a los efectos de adquirir insumos o servicios, comercializar o realizar otras actividades económicas; c) asociarse para gestionar bienes estatales cedidos bajo derechos limitados; d) una combinación de anteriores.

Estas modalidades de creación tienden a semejar el concierto concepcional cooperativo, en lo concerniente a la integración de personas y bienes con el fin de gestionarlos en forma cooperativa.

Lo anterior expuesto facilita evaluar tanto, un panorama legal sobre la propiedad cooperativa en las tradicionales cooperativas agropecuarias nacionales, ajeno a la naturaleza, contenido y fines del fenómeno cooperativo; como avances en el pensamiento del Partido y el Estado Cubano, sobre el fenómeno cooperativo, ${ }^{27}$ expresado como voluntad política en el cuerpo legal de las nuevas cooperativas no agropecuarias ${ }^{28}$; particularidades

27 Es válido en el socialismo la coexistencia de tantas formas económicas y tantas modalidades de percibir lícitamente ingresos personales y empresariales como procedan, para de esa manera garantizar el desarrollo ético, moral, ideológico y socioeconómico de la sociedad socialista.

28 Decreto Ley No. 309/12. 
y avances que se apreciarán en el análisis del contenido de la propiedad que a seguidas se realiza.

\section{Del contenido de la propiedad cooperativa}

El Artículo 146 del Código Civil entraña, también, uno de los problemas medulares del contenido de la propiedad la cooperativa en Cuba, al estar vinculada a la lógica estatalizada de la economía nacional en tres esferas básicas de observación: la determinación del contenido explícito del ejercicio del derecho de propiedad cooperativa: poseer, usar, disfrutar y disponer conforme su destino socioeconómico; ${ }^{29}$ su sujeción a la ley, sus reglamentos y otras disposiciones legales; ${ }^{30} \mathrm{y}$, direccionarla, desde el propio CC, hacia lo agropecuario en los subsiguientes artículos 148 y 149 .

Normativa, cuyo posterior desarrollo en las normas cooperativas, somete el ejercicio de dichas facultades en consonancia a las cualidades de las clases ${ }^{31}$ de cooperativas: Cooperativas de Producción Agropecuarias (CPA), Cooperativas de Créditos y Servicios (CCS), Unidades Básicas de Producción Cooperativa (UBPC). El análisis se realiza con las determinadas extensiones que marcan las regulaciones particulares de esas clases de cooperativas, la supletoriedad declarada del Código Civil establecido en su Disposición Final Primera; las necesarias e imprescindibles transformaciones que las cooperativas y, por qué no, el propio Código Civil, tendrán que sufrir en un futuro cercano, tal como presta a conocimiento la realidad socioeconómica actual y la voluntad política manifestada en los Lineamientos del VI Congreso del PCC; ${ }^{32}$ y, por último, la inclusión en este ambiente cooperativo cubano de las regulaciones para las Cooperativas no Agropecuarias (CNA).

Pues, si se acepta el derecho real o derecho de propiedad cual personificación de un poder jurídico pleno, total, completo, del sujeto sobre el bien objeto de él; éste solo puede ser limitado por la ley concebida, «desde

29 Art. 129. 1, Código Civil.

30 Art. 146, Código Civil.

${ }^{31}$ El término «clase de cooperativa» puede aplicarse en sentido estricto a la índole o contenido de su actividad: producción, consumo, servicios, créditos, protección de riesgos (mutuales); o, en sentido amplio, al tipo específico de cooperativa según la actividad económica concreta: producción, trabajo asociado, agrario, consumo, ventas, pesca, vivienda, explotación comunitaria de la tierra, servicios (financieros, riesgos, créditos, transporte, otros).

32 Lineamientos de la política económica y social del Partido y la Revolución. Folleto. Periódico Granma. 18 de abril de 2011. La Habana. 
el punto de vista de la realidad social actual» (Moreno, B. 1995); entonces, su contenido estará integrado por el libre ejercicio de las precisas facultades fundamentales de poseer, usar, disfrutar y disponer.

En tanto y sin pretensiones conclusivas ni litigantes, al solo efecto de posición doctrinal, se observa ser usual que esas facultades, concebidas cuales contenido del derecho de propiedad, totalizan aptitudes o potestades para realizar, o no, actos jurídicos válidos; así, poseer facultades no significa generar obligaciones, excepto caso que ellas se conciban para realizar un acto jurídico de naturaleza obligatoria. Acto jurídico cuya razón de ser obre en una obligación de hacer, o no. Lo anterior se aprecia cuando el investido de una facultad, puede ejercerla o no; igual ocurre por sus consecuencias, al implicar que el no estar investido de facultad para hacer algo, pero que como tal se realiza, el acto jurídico resultante no tiene validez, es nulo.

A contrario de ser titular de un derecho, que por serlo, sí implica un sistema jurídico obligacional, pues ellos por sí generan obligaciones de Derecho, conforme la titularidad que brinde. Y, en su caso, ejercer un derecho sin ser titular de él, resulta entonces en un acto jurídico ilícito.

En síntesis, tal se visualiza la diferencia entre facultad y derecho.

Diferencia sustantiva, cual punto de incertidumbre al tratar el contenido del derecho de propiedad cooperativa en Cuba, para las tradicionales agropecuarias, que posee consecuencia teóricas y prácticas en dos escenarios; cuando, en el artículo 146 del Código Civil, no se distingue el contenido de la propiedad cooperativa, facultad o derecho, es el primero; el segundo, obra en los sistemas obligacionales de las normas propias de cada clase de cooperativas para el ejercicio de sus relaciones que son representadas en obligaciones con el Estado. ${ }^{33}$

La ausencia de tal distinción legal, en el Código Civil, ha facilitado que los andamiajes legales cooperativos, vuelquen el contenido de la propiedad cooperativa en un sistema obligacional para el sujeto cooperativo y no cual, a verdadero tenor, como facultades del derecho de propiedad.

Lo es pues, en el artículo 146, aparecen dos bloques de contenido; el primero al reglar, lo que se puede entender como el contenido de la propiedad cooperativa, simplemente como que «las cooperativa poseen, usan, disfrutan y disponen de los bienes de su propiedad», ${ }^{34}$ sin proclamarlos derechos o facultades. Lo que no es igual a los derechos de pose-

\footnotetext{
33 Art. 16, Ley 95/02.

34 Art. 146, Código Civil.
} 
sión, uso, disfrute y disposición, en tanto estos tienen su propia significancia.

El segundo, que tal contenido al estar sujeto a «la ley, los reglamentos y otras disposiciones legales» ${ }^{35}$ posee diferente connotación y consecuencias que la sujeción establecida por el artículo 129.1 al estipularlo "conforme su destino socioeconómico.» ${ }^{36}$

Poseer, usar, disfrutar y disponer de los bienes, como facultades, implica el ejercicio de relaciones directas del sujeto titular, como se puntualizó; relación directa apreciada en dos extensiones: poder exclusivo sobre el bien y las consecuencias benéficas o adversas que para el titular resultan de su ejercicio o no, es uno; otra, la sujeción o sometimientos al interés general supremo y precedente al interés particular del sujeto cooperativo, conforme los límites legales.

En tanto la categoría destino socioeconómico, empleada por el artículo 129, aun no estando constitucionalmente asentada, ni conocerse conceptualizada en la terminología económica y jurídica habitual, ${ }^{37}$ también se emplea en los artículos 132, 166.2, 193.2, con objeto diferente.

Ahora, lo determinante en el artículo 129, antes citado, es que destino socioeconómico se asume semejante a función social de la propiedad; ${ }^{38}$ totalizando todos los asuntos de la sociedad; así abarca tanto percepciones, intereses, problemas, necesidades, etc.; sea de los ciudadanos individualizados, segmentos de la ciudadanía o la sociedad en conjunto, como para asuntos en lo social o en lo económico o en ambos, y en los que el Estado viene obligado a intervenir, gestionar o solucionar.

Resulta entonces que, función social y destino socioeconómico, son categorías más abarcadoras e inclusivas que interés social, que utilidad pública, que interés público, privado, etc. El estado viene obligado a acoger sus componentes para, desde la acción estatal propia, a través de la administración pública, o los privados, se satisfagan los asuntos pertinentes; incluyendo determinadas actividades productivas, de servicios, etc. no rentables requeridas para solucionarlos.

35 Art. 146, Código Civil.

36 Art. 129.1, Código Civil.

37 En la doctrina jurídica y económica, existen autores que emplean el término socioeconómico tanto con el fin de abreviar la connotación abarcadora del universo de los social y lo económico, como a los efectos de identificar diversas características, funciones o actividades de las personas, los estados, las instituciones, sociedades, etc., asimilándole la connotación que se hace en el presente.

38 Empleada usualmente en el ámbito político, jurídico y económico; así como en lo normativo. 
Sea cual fuere la acepción del término socioeconómico empleado, connota distanciamiento de las reservas insertas en la «sujeción explícita a la ley, los reglamentos y otras disposiciones legales» reglado; ésta «sujeción explícita» conduce a sujetar el ejercicio de la relación jurídica a las determinaciones estales o administrativas, sean fruto de la racionalidad, de la coyuntura, de los intereses sectoriales o de las parcializaciones administrativas. Situación recurrente en el ambiente cooperativo agropecuario tradicional y el económico nacional, como se tratará a seguidas.

La condiciones generadas por las concretas históricas circunstancias, la visión política y la égida legal ${ }^{39}$ de la planificación directiva del período, inspiraron la promulgación del Código Civil, pese que ya en esa época, tal diseño de política económica legal no era funcional, estaba obsoleto y desvinculado de la realidad social; condición legal civil aún presente no obstante las modificaciones constitucionales de 1992,40 y que pesan sobre la economía y la sociedad cubana y el ambiente cooperativo.

Muestra de ello son las fuentes legales y otras normas tales el Decreto Ley 125/91, ${ }^{41}$ la Resolución 24/91, ${ }^{42}$ y otras reglamentarias; así el asidero del Código Civil como fuente de las CNA.

39 Constitución de la República, 1976, «Artículo 16: El Estado organiza, dirige y controla la actividad económica nacional de acuerdo con el Plan Único de Desarrollo Económico y Social, en cuya elaboración y ejecución participan activa y conscientemente los trabajadores de todas las ramas de la economía y de las demás esferas de la vida social.

El desarrollo de la economía sirve a los fines de fortalecer el sistema socialista, satisfacer cada vez mejor las necesidades materiales y culturales de la sociedad y los ciudadanos, promover el desenvolvimiento de la personalidad humana y de su dignidad, el avance y la seguridad del país y de la capacidad nacional para cumplir los deberes internacionalistas de nuestro pueblo.»

40 Constitución de la República, 2002, «Artículo 16. El Estado organiza, dirige y controla la actividad económica nacional conforme a un el Plan que garantice el desarrollo programado del país a fin de fortalecer el sistema socialista, satisfacer cada vez mejor las necesidades materiales y culturales de la sociedad y los ciudadanos, promover el desenvolvimiento de la persona humana y de su dignidad, el avance y la seguridad del país. En la elaboración y ejecución de los programas de producción y desarrollo, participan activa y conscientemente los trabajadores de todas las ramas de la economía y de las demás esferas de la vida social.»

41 Decreto Ley 125/91. Del Régimen de Posesión, Propiedad y Herencia de Bienes Agropecuarios.

42 Resolución 24/91. Ministro de la Agricultura. Reglamento para la aplicación del Régimen de Posesión, Propiedad y Herencia de la Tierra. 


\section{Breves acerca del contenido del Derecho de Propiedad Cooperativa}

\subsection{Poseer}

Para Lasarte (1993), la posesión es un derecho provisional al que la ley le atribuye efectos; Rivero ( 2005), siguiendo la formulación del artículo 196 del Código Civil cubano, expresa que «La posesión es, ante todo, un estado de hecho o situación material perceptible por los sentidos.» Situación de hecho, en el derecho de posesión o en el derecho a poseer.

En ambos entrańa la relación entre el sujeto y el bien aunque no son iguales, «sea para ejercer una titularidad jurídica o para constituir la facultad del propietario a tener el bien» (Moreno, B. 1995).

Ahora, cual facultad, poseer, tener, ejercer el poder de la tenencia sobre los bienes, por sí, no supone ningún proceder, en sede que ello tiene un fin, un objetivo utilitario: se posee para ejercer o no acciones sobre lo poseído y, en su caso, el usar, disfrutar y disponer de ellos, conforme las facultades que invisten el derecho real en una u otra extensión. Sea el ejercicio o no de la facultad conforme la titularidad que se ostente, la clase de bien y del sujeto concreto.

Para lo cooperativo, es la facultad inherente al contenido de la titularidad cooperativa para tener los bienes en la condición legalmente establecida, conforme la clase de cooperativa.

\subsection{Usar}

Usar (Rivero, O. 2005): «es darle a los bienes su destino o función de acuerdo con su naturaleza, con la voluntad de su titular, o con las reglas legales y sociales vinculantes.» Como la facultad es usar, utilizar, emplear o hacer servir, o para algo, o no, el bien que se posee. Desde lo jurídico cooperativo, conforme a sus cualidades, su destino legalmente establecido y la clase de cooperativa: agropecuaria o no agropecuaria, posibilitando el mejoramiento y acrecentamiento del bien.

\subsection{Disfrutar}

Se entiende, siguiendo a Rivero, ( 2005), como «un beneficio adicional al uso de la cosa misma, implica la posibilidad de hacer entrar en el patrimonio del sujeto otro bien en propiedad, además de aquel que ya lo generó. Disfrutar, a mi entender, es adquirir en propiedad los frutos generados por una cosa propia o ajena». 
En efecto, mediante el uso el bien se mejora y acrecienta; mediante el disfrute, el titular se apropia de los frutos generados por ese uso y los beneficios de su colocación en el tráfico, resultando entonces el acrecentamiento de la masa patrimonial cooperativa por el incremento del valor del bien.

\subsection{Disponer}

Atributo originario de la propiedad, materializa el poder sobre el bien, en tanto el propietario puede realizar cualesquiera acciones sobre él, en cuanto no estén prohibidas por la ley, transmitirlo bajo cualquier forma, consumirlo, etc.; incluyendo las determinaciones testamentarias; «así podrá venderla, donarla, gravarla o transformarla, de acuerdo con los límites que pueda tener» (Moreno, B 1995).

Por la especial protección de los bienes, en el ámbito agropecuario, es también una de asuntos controversiales en lo cooperativo cubano, ceñida, en eso sí, la facultad dispositiva del complejo sistema administrativo, incluyendo los actos sucesorios, de los cuales se excluye la testamentaria. ${ }^{43}$

\section{Posesión, uso y disfrute en las cooperativa agropecuarias}

Del análisis del ejercicio de la posesión, uso y disfrute de los bienes de las cooperativas agrarias, resulta que están sujetas a un régimen simplificado de directrices obligatorias, tanto sobre las tierras como sobre los bienes agropecuarios. ${ }^{44}$ Ese diseño obligacional, para las cooperativas agrarias, CPA, CCS y UBPC, es consecuencias de considerarse insertadas «en el sistema de organizaciones primarias de la producción agropecuaria del país»; ${ }^{45}$ en consecuencias sometidas al Plan. Diseño obligacional que también marca su ejercicio para los integrantes.

\subsection{Cooperativas de Producción Agropecuaria (CPA), Cooperativas de Créditos y Servicios (CCS) y Unidades básicas de Producción Cooperativa (UBPC)}

\subsubsection{Para las cooperativas}

Como se apuntó, las CPA y las CCS, poseen su fuente legal en el artículo 20 de la Constitución de la República y su vigente norma de desarrollo es la Ley 95/02; ley, que si bien ostenta una estructura aceptable,

\footnotetext{
43 Art. 128, Decreto Ley 125/91.

44 Art. 22, Res. 574/12, Ministro de la Agricultura.

45 Art. 16, Ley 95/02.
} 
posee defectos de contenido y fines caracterizadores del fenómeno cooperativo, incluyendo creación y funcionamiento sujeto al mandato estatal; ahora bien, en virtud de los deslices en su redacción están posibilitadas a que hoy se palpen ciertas tolerancias de actuación.

En su Capítulo 4, al establecer las relaciones de la cooperativa con los órganos y organismos del Estado, etiqueta la naturaleza obligacional de las facultades de posesión, uso y disfrute. Análogo se manifiesta para los otros dos escenarios de relaciones: con las empresas estatales, y con los órganos locales del Poder Popular.

El artículo 16 dispone, taxativamente, quince obligaciones de la cooperativa con el Estado y otros entes públicos, cuyos verbos rectores: usar, utilizar, explotar, elaborar, proponer, vender, contratar, adquirir, cumplir, aplicar, etc. son expresión de ello.

Resulta paradójico que, para el Estado el sistema relacional se ciñá a brindarles apoyo, en sus acciones para la constitución, desarrollo y fortalecimiento de las cooperativas, tales como entregas de tierras, prestaciones, asistencia técnica, etc., condicionadas a la posibilidad de brindárselo. ${ }^{46}$

Pese que, con las empresas estatales, el sistema relacional se declara contractual, entre sujetos con igualdad jurídica bidireccional, compra de producciones, el uno, adquisiciones de insumos, el otro, es evidente el desequilibrio manifiesto en que la cooperativa es la parte menos favorecida, estando condicionada, la relación contractual, a la política y disposiciones que dicte el Ministerio de la Agricultura para la empresa. ${ }^{47}$

Las relaciones con los Órganos Locales, también imprecisas, están sujetas al plan o encargo y control estatal; en ello se inscribe el carácter obligacional de las facultades; de hecho, hoy existen ciertas flexibilidades por parte de estos Órganos.

La creación de las UBPC, mediante el Decreto Ley No. 142/93, fue una de las respuestas, del Estado cubano ante la Crisis económica de la década del 90, consistió en la desmembración de las macroempresas agropecuarias estatales; esa norma vino a engrosar el ambiente cooperativo nacional, acrecentando la dispersión legal de estos sujetos.

Tal clase de cooperativa posee características semejantes a las CPA ${ }^{48}$ en su creación, estructura y funcionamiento; se diferencia en la tenencia de los bienes conforme su naturaleza atemperándose a los precep-

46 Art. 18, Ley 95/02.

47 Art. 20, Ley 95/02.

48 Las UBPC, como otro modelo cooperativo, se sustenta en lo jurídico formal en dos categorías de derechos reales: usufructo de la tierra y propiedad de la producción y del resto de los bienes agropecuarios y su diseńo obedece, como apunta Valdés Paz (1999. p 26) a la óptica organizativa, de gestión y normativa similar a las CPA. 
tos constitucionales; ${ }^{49}$ así la tierra se transmite en carácter de usufructo por tiempo ilimitado; y, los bienes agropecuarios, los frutos que genera la tierra, los recursos financieros y otros derechos sobre ellos, son de su propiedad e integran el patrimonio. ${ }^{50}$

En un primer momento, el Acuerdo del Comité Ejecutivo del Consejo de Ministro, ${ }^{51}$ transfirió a los Ministros de la Agricultura y del Azúcar, la facultad de reglamentarlas, es a partir de la extinción de este último, ${ }^{52}$ tal facultad residió solo en el Ministro de la Agricultura, ${ }^{53}$ que a su amparo, dictó la Resolución No. 574/12, Reglamento General de las Unidades Básicas de Producción Cooperativa, que abarca todas las constituidas en el país, con independencia de que su tipo de producción, sea agropecuaria, cañera o forestal.

En ellas, el ejercicio de las facultades de posesión, uso y disfrute de los bienes, de los cuales se exceptúa la tierra, está sujeto un régimen simplificado de facultades obligatorias, tanto sobre otros bienes inmuebles como sobre los bienes agropecuarios, ${ }^{54}$ al igual que para el resto cooperativo agropecuario.

\subsubsection{PARA LOS MIEMBROS}

Tanto en las CPA como las UBPC, sus integrantes, al no ser titulares de bienes y no poseer obligación de aporte patrimonial, solo aportando su fuerza de trabajo, no están representadas facultades sobre bienes, debiendo cumplir sus prestaciones de trabajo y exigir sus derechos.

En las CCS, donde sus miembros sí son titulares de bienes, estas se representan bajo un régimen cerrado, que significa poseerlo, usarlo y disfrutarlo dirigido, en exclusiva, a la ejecución y realización de la producción agropecuaria sujeta al Plan. ${ }^{55}$

\subsection{La disposición}

\subsubsection{PARA LaS COOPERATIVAS}

Derivado de la integración del patrimonio cooperativo y de la cualidad de los miembros, así opera la facultad dispositiva en las CPA y CCS;

49 Art. 15.b), Constitución de la República de Cuba.

50 Art. 13, Res. 574/12, Ministro de la Agricultura.

51 Acuerdo del Consejo de Ministros de 20 de septiembre de 1993.

52 Decreto-Ley No. 287/11, «De la Extinción del Ministerio del Azúcar».

53 El Acuerdo No. 7271 del Comité Ejecutivo del Consejo de Ministro, de fecha 19 de julio de 2012, facultó al Ministro de la Agricultura para reglamentar a las UBPC.

54 Art. 22, Res. 574/12, Ministro de la Agricultura.

55 Art. 3.c), 9.a), c), 16.c), 19.b), Ley 95/02. 
concorde la disposición del artículo 20 de la Constitución, las tierras de las cooperativas constituyen un bien especialmente protegido, tanto las declara inembargables y exentas de gravámenes, como ciñen su transmisión solo a otras cooperativas o al Estado. En las UBPC, al ser la tierra propiedad estatal, transferidas en usufructo, por su naturaleza operan idénticas protecciones.

El desarrollo del precepto anterior ${ }^{56}$ para las CPA, establece 5 modos de transmisión de la tierra: a) permuta entre cooperativas; b) permuta entre una cooperativa y el Estado; c) compraventa entre cooperativas; ch) fusión y división de cooperativas; y d) venta al Estado; otorgándose facultad excepcional al Ministro de la Agricultura, no ajustada al precepto constitucional para, por causa de utilidad pública o interés social, autorizar otras transmisiones de estas tierras. También las cooperativas pueden disponer de la tierra de su propiedad para conceder a sus miembros derechos de superficie para construcción de vivienda. ${ }^{57}$ Las UBPC, operan bajo similar régimen.

En la CCS, también propietaria de una pequeña masa patrimonial, compuesta por bienes agropecuarios, soporte necesario de las actividades del desempeño de su función de intermediación secundaria, excepto la tierra, su disposición se ajusta a iguales prescripciones que en la CPA, es decir, al Estado o a otra cooperativa.

En las UBPC, es más evidente la carencia de la facultad dispositiva; no obstante, a semejanza de las CPA, pueden proponer su fusión, división y disolución, sujetas al régimen de autorización ministerial.

\subsubsection{Para los miembros}

La CPA, que consiste en un patrimonio con personalidad jurídica, propietaria formal de una masa patrimonial integrada por la tierra y otros bienes agropecuarios y sus frutos, que incluye solo los frutos de bienes estatales recibidos en usufructo, donde los miembros solo son propietarios de su fuerza de trabajo, el beneficio de la facultad dispositiva solo resulta para aquellos bienes agropecuarios constitutivos de bienes pecuniarios en débitos pendientes, como son los anticipos no percibidos, la participación en las utilidades no distribuidas en el período y la amortización pendiente de pago de los bienes aportados, ${ }^{58}$ en la actualidad no existente, que son transmisibles a efectos sucesorios.

56 Art. 5, Decreto Ley No. 125/91.

57 Art. 220, Código Civil.

58 Art. 34, Decreto Ley 125/91. 
Sobre ellos se realizan dos llamados: el primero a los herederos vinculados con la cooperativa o que posean dependencia económica del causante; y, caso de inexistencia, a aquellos que corresponda conforme la legislación civil común, deducida de su cuantía las obligaciones tenidas con el Banco.

La transmisión de la vivienda recibe un tratamiento específico, caso de fallecimiento, conforme lo prescito en la legislación especial vigente.

Los miembros de las UBPC, en tanto prestatarios de la fuerza de trabajo, solo los bienes pecuniarios pendientes de pago, son transmisibles a sus familiares por causa de muerte, así como los beneficios de la Seguridad Social común.

En las CCS, en virtud de las titularidades de sus miembros como propietario o usufructuario de la tierra y otros bienes agropecuarios, la disposición sobre ellos genera particularidades en su ejercicio y, con ello, diversos tratamientos legales.

El ejercicio de disponer de la tierra por los miembros de las CCS, se identifica al de los agricultores individuales y el resto cooperativo, aunque muestra mayor complejidad, por razón de la existencia de a) diferentes clases de bienes — tierras y bienes agropecuarios—; y, b) diferentes cualidades de los miembros que la integran.

Siendo notable que, con el fin de mantener el carácter indivisible de la tierra, el miembro propietario de tierra y otros bienes agropecuarios, puede disponer de ella bajo dos requisitos; el primero, conforme las tradicionales opciones de: a) incorporarla a una CPA; b) venderla; c) permutarla; y d) otra forma de transmisión al Estado, a CPA, a otro agricultor pequeño; el segundo, condicionado a la previa autorización estatal; un tercero especialísimo es la satisfacción de otro interés social debidamente fundamentado, como en la CPA, cuando exista. ${ }^{59}$ Sin perjuicio de la opción del derecho de adquisición estatal preferente. ${ }^{60}$

Las transmisiones de los bienes agropecuarios del pequeño agricultor, siguen idéntico régimen, sean propietarios o usufructuarios de tierras, pues aunque la Constitución reconoce los derechos sucesorios en general, en especial dada la naturaleza de la tierra y los bienes agropecuarios, está prohibida la sucesión testamentaria, ${ }^{61}$ bifurcándose su expresión en dos direcciones: la una es la heredabilidad; la otra la adjudicabilidad.

Esos efectos los bienes se clasifican en tierra, bienes relacionados con su explotación y no relacionados con ella. Así, al fallecimiento del pe-

59 Arts. 6, 12, 13 y 14, Decreto Ley 125/91.

60 Art. 19 de la Constitución de la República; Disposición Especial Primera, Decreto Ley $125 / 91$.

61 Art. 28, Decreto Ley 125/91. 
queño agricultor propietario de tierra, bienes agropecuarios y otros bienes no relacionados con la explotación agraria, su transmisión posee sus peculiaridades. Primero, está prohibida la sucesión testamentaria ordinaria de la tierra y demás bienes agropecuarios; segundo, la tierra y los bienes agropecuarios, son heredables y adjudicables a los herederos que la trabajan, salvo excepciones; ${ }^{62}$ tercero, se reconoce el derecho a la adjudicación del importe del valor de esas tierra y bienes agropecuarios por aquellos herederos que habiendo dependido económicamente del fallecido, no cumplan los requisitos exigidos para serles adjudicados; ${ }^{63}$ cuarto, por excepción, se reconoce el derecho de adjudicación para el heredero no adjudicable que demuestre que, a futuro cierto, podrá incorporarse a trabajar la tierra. ${ }^{64} \mathrm{Y}$, quinto, la sustanciación del proceso sucesorio de la tierra y demás bienes agropecuarios, es de carácter administrativo. ${ }^{65}$

Para el caso del miembro de la CCS usufructuario de tierra fallecido, por su naturaleza, los bienes agropecuarios imprescindibles para hacerla producir de su propiedad, no son adjudicables a sus herederos, sino transferidos al Estado, ${ }^{66}$ reconociéndose, eso sí, el derecho de adjudicación del importe de su precio a sus herederos.

La transmisión del resto de los bienes no vinculados a la explotación de la tierra, será realizada conforme la legislación ordinaria. ${ }^{67}$

\section{Posesión, uso, disfrute y disposición en las Cooperativas No Agropecuarias (CNA)}

\subsection{Previa}

La introducción, en el Modelo de Gestión Económica del país, por los Lineamientos 25 al 29 del VI Congreso del Partido de cooperativas en diferentes sectores económicos, mostró un paso de avance del pensamiento dialectico materialista del Partido y el Estado en la percepción de la realidad socioeconómica nacional concreta, ${ }^{68}$ voluntad política que tiene su

${ }^{62}$ Art. 24, de la Constitución y Art. 18 del Decreto Ley 125/91.

63 Art. 20, Decreto Ley 125/91.

${ }^{64}$ Art. 23, Decreto Ley 125/91.

65 Art. 19, Decreto Ley 125/91.

66 Art. 29, Decreto Ley 125/91.

67 Art. 24, Decreto Ley 121/91.

$68 \mathrm{Si}$ bien las cooperativas surgen en el capitalismo como respuesta de los desposeídos a las aberrantes formas de explotación, en el socialismo surgen por su naturaleza socialista y su capacidad de contribuir al desarrollo ético, moral, ideológico y socioeconómico de la sociedad socialista 
primera y transitoria expresión legal mediante el Decreto Ley No. 305/12, de las Cooperativas no Agropecuarias. ${ }^{69}$

Si con ellas se abrieron las perspectivas del cooperativismo en otros sectores de la economía, incrementando el ambiente cooperativo cubano, a su vez se incrementó la dispersión normativa cooperativa nacional, sumándole los escollos e incógnitas de su lacónica redacción y disfunción de naturaleza y contenido que encierra, no solucionables siquiera acudiendo a su fuente legal o, las profusas remisiones reglamentarias ${ }^{70}$ que contiene.

Notorias son la incertidumbre e incoherencia legal de su régimen de creación; la aparente libertad de asociación que tácitamente contiene, contrastando con la rigurosidad de su régimen de permisión; las causales de formación; la ausencia de capital social para fundar su patrimonio social, sustituido por la categoría capital de trabajo inicial; la inclusión de un régimen de licitación; ${ }^{71}$ las reiteradas remisiones estatutarias; la ausencia de mención no lucrativa y de educación cooperativa; y otras que son germen de las presunciones que caracterizarán la interpretación en el desarrollo de la existencia y actuar de estas cooperativas.

Sin embargo, para Puyo, A.M. ( 2014) «es importante reconocer que representan un gran avance, fundamentalmente por el hecho de abrir la posibilidad de constituir cooperativas en otros sectores de la economía distintos al agrario.»

Siendo así, comentar acerca del poseer, usar, disfrutar y disponer los bienes de las CNA se embrolla además, por estar la norma bajo la disciplina economicista, manifiesta en la lógica que la guía, que desdice los principios y valores sociológicos del cooperativismo; en especial su naturaleza no lucrativa, su proyección social, la educación, que genera dudas sobre que se inclinen a la mercantilización o la estatalización.

A seguidas se comentan, desde la síntesis, sobre el ejercicio esos derechos en las tres modalidades de formación básicas de las CNA; la cuarta se presupone una mezcla de ellas. ${ }^{72}$

${ }^{69}$ Decreto Ley 309 del 2012. G.O Gaceta Oficial No. 053 Extraordinaria de 11 de diciembre de 2012.

70 Arts. 3, 24.1, 31, Decreto Ley 305/12; Arts. 9.1), 16.2, 18, 20, 21, 21, 22, 27, 28, 29, 31, 34.3, 5, 34.1, 35, 36.3, 37.d), j), 38, 39, 40, 41, 42, 43. 1 j), 44, 46, 47, 57.3, 61, 67.a), 68, 77, Decreto 309/12.

${ }^{71}$ Art. 9, Decreto Ley 305/12; Arts. 6.1, 13, del Decreto 309/12; Res. 570/12, del Ministro de Economía y Planificación.

${ }^{72}$ Art. 6, Decreto Ley 309/12 


\subsection{Primera modalidad}

La primera modalidad que se nomina, ${ }^{73}$ surge del patrimonio generado por los aportes dinerarios de los socios; aporte dirigido la adquisición de bienes, denominado capital de trabajo inicial, y derechos necesarios para la constitución, asentamiento y desarrollo de la cooperativa; concepción aceptable del aporte por constituir éste el primer sustrato utilitario destinado a la formación del patrimonio propio, uno de los elementos esenciales de la persona jurídica cooperativa, aunque en este caso no se identifica como capital social.

La incertidumbre legal del ejercicio de esas facultades se manifiesta desde su origen, al destinarse el aporte de los socios a construir la retomada categoría propiedad colectiva; categoría política jurídica empleada en el artículo 20 de la Constitución de la República hasta 1992, que en su modificación fue sustituida por la de producción socialista, conforme los argumentos expuestos por los Diputados. ${ }^{74} \mathrm{Y}$, pese carecer de conceptualización filosófica o política, se replicó en el Lineamiento 25 del VI Congreso PCC.

Es presumible que el ejercicio de los derechos sobre bienes, incluidos en el patrimonio cooperativo, esté direccionado a cumplir su objeto social, consistente en las producciones, actividades de prestación de servicios o comercialización que realizará la cooperativa ${ }^{75} \mathrm{y}$, en correspondencia a ello, será el ejercicio de las facultades dimanadas.

No es evidente la intromisión estatal sobre el régimen de actividad de la cooperativa no agropecuaria, ${ }^{76}$ posibilitando la libertad del ejercicio de las facultades contenidas en el derecho de propiedad en esta modalidad, a los

73 Arts. 6 a), 21.1 y 22, Decreto Ley 309/12.

${ }^{74} \mathrm{La}$ categoría propiedad colectiva no es usual en la normativa cubana, excepto en el artículo 20 de la Constitución de 1976, que declaró la propiedad cooperativa como «una forma de propiedad colectiva»; categoría abandonada en las modificaciones de 1992, pues los Diputados hicieron hincapié por no exaltar el término «propiedad», sino el de forma de "producción socialista», más acorde con la naturaleza cooperativa. Acta de la Asamblea Nacional del Poder Popular acerca de las modificaciones constitucionales. Pág. 20, 21. La Habana. 1992. También el término obra en el artículo 43 de la Ley Especial de Asociaciones Cooperativas, de 2-7-01 de Venezuela, que expresa "Las asociaciones cooperativas son empresas de propiedad colectiva».

En la terminología política nacional y foránea es también poco usual; su empleo refleja determinismos políticos, equiparándola a propiedad social, propiedad del pueblo, propiedad de todos, etc. como partes integrantes de discursos políticos, pero sin que se conozca científica conceptualización. Por lo general significa, explícita o implícitamente, intromisión estatal en los asuntos económicos, para transformar la propiedad privada sobre los medios de producción, en otra forma de propiedad, sea colectiva, del pueblo, cooperativa, etc.; y, con ello la transformación de forma de producción capitalista en forma de producción socialista.

75 Art. 14, Decreto 309/12.

76 Excepto la prioridad debida en la planificación y su cumplimiento del encargo estatal cuando proceda, conforme se percibe en el art. 55 del Decreto 309/12. 
efectos de poseer, usar y disfrutar libremente; así los socios acuerdan decidir la organización, planificación y ejecución de sus actividades de producción y/o servicios; en correspondencia a ello lo serán sus ingresos y gastos. ${ }^{77}$

La facultad de disponer es más controversial, sea para la cooperativa, sea para los socios. Para la cooperativa está sujeta a la línea política administrativista patrimonial del pensamiento oficial, ${ }^{78}$ se refleja, desde lo legal, en las modalidades de creación y en la extremadamente compleja tela de araña del sistema de autorización para autorizarlas; también se advierte, entre otras, en la tendencia de la construcción de una propiedad cooperativa; ${ }^{79}$ en caso de su disolución y liquidación; ${ }^{80}$ que significa para los socios ${ }^{81}$ el derecho a solicitarla a través de la Asamblea General, ${ }^{82}$ más es la Autoridad de Aplicación quién lo decide y autoriza. ${ }^{83}$

No aparecen referencias normativas expresas acerca del reintegro del valor del aporte dinerario del socio para constituir el patrimonio cooperativo; solo tratan, ante diversas variantes de la pérdida de condición de socio el pago de anticipos y utilidades pendientes y adeudos por bienes vendidos a la cooperativa. ${ }^{84}$ En el supuesto de liquidación, además de honrar las obligaciones pendientes, el resto poseerá un destino estatutario. ${ }^{85}$

\subsection{Segunda modalidad}

La segunda modalidad, fijada en el artículo 6.b) del Decreto Ley 305 exhibe, así mismo, percepciones desacertadas en el enfoque de los fines de la cooperativa; consiste en la adquisición de insumos y colocación de los productos y servicios, resultas del trabajo individual, en el tráfico comercial, manteniendo los socios la propiedad de sus bienes, ${ }^{86} \sin$ mención a re-

77 Art. 20, Decreto Ley 305/12; arts. 28.f), 33.4, 38.h), 43.a), b), d), 54 y 55, Decreto 309/12.

${ }^{78}$ La voluntad política, manifestada en el Lineamiento 26 del VI Congreso del Partido fija «La norma jurídica sobre cooperativas deberá garantizar que éstas, como propiedad social, no sean vendidas, ni trasmitida su posesión a otras cooperativas, a formas de gestión no estatal o a personas naturales»; cuya expresión legal tácita obra en las modalidades establecidas en el artículo 6 y el sistema de autorización previstos en los artículos 11 al 16 del Decreto Ley 305/12, reglamentado por el Decreto 309/12.

\footnotetext{
79 Art. 31, Decreto 309/12.

80 Art. 30 y 32, Decreto Ley 305/12.

81 Art. 21.s), Decreto 309/12.

82 Art. 37.i), Decreto 309/12.

83 Art. 75, Decreto 309/12.

84 Art. 31, Decreto 309/12.

85 Art. 77, Decreto 309/12.

${ }^{86}$ Art. 6.b), Decreto Ley 305/12.
} 
querimientos básicos de la creación, organización y funcionamiento de la cooperativa, entre ellos el capital social, patrimonio social, domicilio, etc. no obstante su luego remisión estatutaria. ${ }^{87}$

$\mathrm{Al}$ solo efecto de apunte, la norma expresa un imposible real y legal: asociarse y serle otorgada personalidad jurídica a un sujeto socioeconómico, sin mención de patrimonial, domicilio, etc. Imposible real pues constituyen requerimientos para su organización y funcionamiento; legal, entre otras, como garantía del cumplimiento de sus obligaciones y sustento de su responsabilidad.

Retomando el objeto de estudio, el ejercicio de las facultades de poseer, usar y disfrutar, se atendría a dos escenarios: la cooperativa, sobre aquellos bienes y derechos constitutivos del necesario patrimonio social; los socios, individualmente sobre los bienes de cada uno, lo cual no se diferencia con el resto de los trabajadores por cuenta propia, con ello no hay percepción de movilidad ascendente de status concepcional ni real, entre cualidad de socio o trabajador individual.

La facultad dispositiva de la cooperativa, se atendería a las prescripciones estatutarias, conforme se remite; ${ }^{88}$ de los socios, no existe prescripción legal, por los que deduce la aplicación de régimen común.

\subsection{Tercera modalidad}

La tercera modalidad no encierra, en principio, modalidad asociativa; ella se genera cuando exista el requerimiento de administrar y gestionar en forma cooperativa bienes estatales, ${ }^{89}$ sea en la ejecución de actividades productivas o de servicios que en forma estatal se realizaba, mediante la adhesión de personas naturales, con preferencia los propios anteriormente trabajadores asalariados, con intención de ser socios de esa opción de cooperativa.

Modalidad que implica la creación de una cooperativa de trabajo, a instancia estatal. ${ }^{90}$

87 Art, 21.d), h), k), Decreto Ley 305/12.

88 Art. 21.s), Decreto Ley 305/12 y 77, Decreto 309/12.

89 Art. 6.c), Decreto Ley 305/12.

90 Modalidad análoga fue gestada en Argentina, en los últimos años de la década del 90, cuando grupos de trabajadores frente la crisis económica y social asumieron la decisión de tomar las empresas abandonadas por sus propietarios, denominando a su movimiento «empresas recuperadas por sus trabajadores», ERT; muchas adoptaron la forma de cooperativas de trabajo, colocando de forma asociada su trabajo para la administración, gestión y actividad productiva o servicios, con el fin de garantizar empleo, salario, nivel de vida, conquistas sociales, etc. En el caso Cuba diverge totalmente causa, naturaleza, contenido y fines, en tanto difieren en su origen y poseen el beneficio del impulso político administrativo y la protección legal, económica y social que les otorga el Estado. 
Para la cooperativa el régimen de posesión, uso, disfrute y disposición de los bienes, se ciñe a lo establecido para el tipo legal de transmisión de otros derechos sobre los bienes de propiedad estatal que se han realizado en el país; ${ }^{91}$ para los socios, su ejercicio tendría remisión estatutaria.

\section{A modo de síntesis conclusiva}

Es, como se observa, tan enrevesado comentar acerca del derecho de propiedad cooperativa como de su contenido cuales son las arquitecturas de redacción, la dispersión de las normas que las estatuyen, la unicidad de sistema de autorización administrativa y su contraste con la apreciación del fenómeno asociativo: acto de aceptación o acto de asociación.

Así el ambiente cooperativo, su normativa y práctica alcanza extremos angustiantes para el pensamiento filosófico jurídico socialista y del fenómeno cooperativo; carecen del basamento en principios y valores unificados, enfoque educativo y expresa declaración al no ánimo de lucro; todo ello contribuye a conducir a lógicas que alejadas del ideario cooperativo para el socialismo. ${ }^{92}$

El caso CNA, además la complejidad deviene de las carencias propias del modelo, por falta de sustento constitucional al derecho genérico de asociación cooperativa, ${ }^{93}$ y una norma cooperativa única, general, casi reglamentaria y ajustada a la naturaleza, contenido y fines del cooperativismo para el socialismo.

La necesidad de promulgar el ordenamiento general cooperativo, fundado en el modelo adecuado, no es acto de mejoramiento legal, es acto de mejoramiento social, encaminado a conjugar la preservación de los principios políticos, económicos y sociales del Estado, la historia y tradición cooperativa cubana y sus componentes esenciales de manera armónica y racional, identificada plenamente con la visión dialéctica materialista de la naturaleza, contenido, alcance, funciones y valores socioeconómicos del cooperativismo en el socialismo.

Por ello, la reflexión dialéctica materialista de la esencia del fenómeno cooperativo, inserto en las condiciones del proyecto socialista cubano, es el proceder obligado para arribar a la apropiada producción legal, que exprese

${ }^{91}$ Art. 15.b) y 17, Constitución de la República de Cuba; Decreto Ley 142/93.

92 Cierto que todas las normas cooperativas (Ley 95/02; Decreto Ley 142/93; Decreto Ley $305 / 12$ )

declaran los principios que la sustentan.

93 Comprobado, además, en la promulgación del Decreto Ley 305/12, que su fuente legal es el Código Civil. 
la voluntad política ${ }^{94}$ de fijar la institución jurídica cooperativa, como instrumento de cambio y vigorización de las relaciones sociales cooperativas y de la sociedad en general; influyendo tanto, en el desarrollo socioeconómico del país sin mengua de la empresa estatal y otras formas de gestión económica, como en la regeneración de la esencia, valores, principios y percepciones del socialismo, bajo la visión de la cooperativa cual sociedad de personas insignia del socialismo.

\section{Bibliografía}

Acuerdo del Consejo de Ministros de 20-9-93.

Acuerdo del Comité Ejecutivo del Consejo de Ministro de 19-7-12.

Constitución de la República de Cuba.

Decreto 203/95, Contravenciones del régimen de posesión, propiedad y herencia de la tierra y bienes agropecuarios y del Registro de la tenencia de la tierra.

Decreto 309/12, Reglamento de las Cooperativas no Agropecuarias de Primer Grado.

Decreto Ley 125/91, Del Régimen de Posesión, Propiedad y Herencia de Bienes Agropecuarios.

Decreto Ley 142/93, Sobre las Unidades Básicas de Producción Cooperativa.

Decreto Ley 287/11, De la Extinción del Ministerio del Azúcar.

Decreto Ley 305/12, De las Cooperativas no Agropecuarias.

Decreto Ley 306/12, Del Régimen Especial de Seguridad Social de los socios de las Cooperativas no Agropecuarias.

Fernández Bulté, Julio (1996). Panel Sobre el Derecho. Revista Temas. 15.

Fernández Bulté, Julio. (1997). Filosofía del Derecho. Ed. Felix Varela. La Habana.

Fernández Peiso, Avelino. (2008). Lecturas en pro del cooperativismo. Ed. Universo Sur. Cienfuegos.

Fernández Peiso, Avelino. (2012). Las Cooperativas. Bases para su legislación en Cuba. Ed. Ciencias Sociales. La Habana.

Kaplan, Drimer. Las Cooperativas. Buenos Aires. 1973.

94 Y la voluntad política (Fernández Bulté, 1977, p. 373, ss) «supone una red de mediaciones entre los hechos económicos, entre las condiciones materiales de vida de la clase supuestamente dominante y su traducción a intereses o valores políticos»; donde, «el contenido de la voluntad política suele ser, sobre todo en las sociedades modernas - y con otros matices también en las sociedades precapitalistas - de un innegable sentido axiológico, es decir, suele ser y se expresa normalmente como contenido de valor, de apreciación y confirmación de valores, no sólo políticos como tales, sino también espirituales en el sentido más general, además de culturales, históricos y hasta éticos». 
Lasarte, Carlos. (1993). Curso de Derecho Civil Patrimonial. Ed. Tecnos S.A. Madrid.

Ley 36/82, Ley de Cooperativas Agropecuarias.

Ley 59/87, Código Civil.

Ley 95/02, Ley de Cooperativas de Producción Agropecuaria y de Créditos y Servicios.

Ley Especial de Asociaciones Cooperativas/01. Venezuela

Lineamientos de la política económica y social del Partido y la Revolución. Folleto. Periódico Granma. 18 de Abril de 2011. La Habana.

Moreno Quesada, Bernardo. (1995). Derecho Civil Patrimonial. Ed. Comares, Granada, España.

Puyo Arluciaga, Ana María. (2013). La Nueva Normativa Cubana de Cooperativas No Agropecuarias. GEZKI-UPV/EHU Revista Vasca de Economía Social. GEZKI/Instituto de cooperativas y economía social de la UPV/EHU. País Vasco. España.

Res. 160/93, Ministro del Azúcar.

Res. 24/91, Ministro de la Agricultura.

Res. 354/93, Ministro de la Agricultura.

Res. 427/12, Ministra de Finanzas y Precios.

Res. 525/03, Ministro del Azúcar.

Res. 570/12, Ministro de Economía y Planificación.

Res. 574/12, Ministro de la Agricultura.

Res. 629/04, Ministro de la Agricultura.

Res. 688/97, Ministro de la Agricultura.

Rivero Valdés, Orlando (2005). Temas de Derechos Reales. Ed. MES. La Habana. 